\title{
Development in diagnosis and treatment of Alzheimer's disease
}

\author{
Kumar Shivam, Amir Riyaz Khan, Pankaj Taneja* \\ Department of Biotechnology,School of Engineering and Technology,ShardaUniversity, GreaterNoida,India \\ "Corresponding author: Associate Professor and Ramalingaswamy fellow, Department of Biotechnology, School \\ of Engineering and Technology, Sharda University
}

\begin{abstract}
The decrease in hippocampal neurogenesis can lead to development of Alzheimer disease (AD), yet various hypothesis suggest that $\mathrm{AD}$ patient have increased neurogenesis in the region 1 of hippocampus proper (CA1 region). Ammon's horn (the principle region of Alzheimer's pathology) has been found to be involved in neuronal loss however the exact nature of neurogenesis is unknown. Insulin like growth factor 1 (IGF-1 are associated with an increased risk of developing AD) stimulates neurogenesis to produce major change in hippocampal plasticity and seems to be involved in Alzheimer's pathology. Allopregnanolone, a neurosteroid, aids in continued neurogenesis in the brain. Levels of allopregnanolone in the brain decline in old age and Alzheimer's disease Allopregnanolone acts by reversing neurogenesis impairment thus preventing cognitive deficitis of $\mathrm{AD}$ disease in various mouse models. Ephirin signaling pathway has been shown to regulate neurogenesis in the hippocampus and have been studied as potential target to treat some symptoms of AD. Molecule associated with the pathology of AD, including Apo lipoprotein (ApoE), presenilin genesPSI,PS2 and APP have also been found to impact adult neurogenesis in the hippocampus. Detection and diagnosis of AD is done by variety of neuro-psychatic and imaging techniques. Psychological, behavioral, cognitive, holistic and humanistic therapy approaches are used for its treatment.
\end{abstract}

Keywords: Neurogenesis, Alzheimer, Neurodegenration, Aging, Adult neurons

\section{INTRODUCTION}

Alzheimer is a disorder which affects the memory. It is a common form of dementia in which 1-3\% of population suffers globally [1]. It is considered as the "greatest disorder of old age" since it affects person predominantly between age of 60 and 65 [2]. WHO ranks $\mathrm{AD}$ among the top three illnesses that contribute to the global burden of disease in economic terms [3]. Due to a very high cost of its treatment it causes a huge monetary loss. It is an untold agony to family members and caregivers imposing a huge responsibility and burden on them. In medical terms medication and other intervention and around 30 percent persons with $\mathrm{AD}$ require treatment all their lives [4]. However the scenario is not all blank. Recent research has at better understanding of AD. Much of an etiology. From psychological theories of causation such as faulty parenting the focus has shifted to anatomical and functional change in the brain. Molecular process growing aberrant in the brain has also been implicated. The study of genomics in AD is a part of the genetics research with an approximate 90 percent hereditary factor involved [5]. The genome wide association studies have revealed several possible risk variants. Most noted among these are on the HLA region [5]. However these do not fully account for the estimated heritability in AD. Gene mapping studies are viewed as critical for the development of factors causing $\mathrm{AD}$ which is hereditarily perplexing and heterogeneous disorder. Mutations in APP, PSEN1, PSEN2 have been found to be involved in early- onset of familial AD while APOE is involved in late-onset AD [6].Moreover AD may develop due to various factors such parental development and obstetric complication. AD can develop in babies born in women with old age [7]. More pollution and more of high risk behavior also seem to increase the risk to develop AD. Neurodevelopment of the infant's brain is susceptible to variety of viral infections such as herpes simplex virus, be an additional risk factor AD. The first trimester of pregnancy can cause increased permeability of cortisol across the placenta may be a risk factor to AD [8]. Increasing evidences show association between obstetric complication low birth weight and a later diagnosis of Alzheimer's in many parts of the world [9]. Parental and perinatal monitoring and interaction can reduce damage to the fetus brain. The Pharmaceutical industry has also been active in the last ten years in doing research on new generation of anti-psychosis drugs for treating AD. However they do have some side effects such as metabolic syndrome 
despite the promise of biological intervention for $\mathrm{AD}$ there are various limitations in treatment strategy of $\mathrm{AD}$ in community. Treatment of $\mathrm{AD}$ cannot be only biological, pharmacological or psychological. It has been more optimism about the outcome of Alzheimer and the fact this is the wide spread acceptance that recovery is not impossible in Alzheimer. Some of the earliest description of the condition resembling Alzheimer's in India was made by ayurvedic physician Charaka over 3330 years ago in the text Charka Samhita. This is corresponded closely with the description in Greek medical test by Hippocrates. Subsequently India's contribution to AD research has not been substantive. The Madras longitudinal study is a landmark study on course and outcome of $\mathrm{AD}$. The patient have been followed up from the first onset for 65 years and study have been generated a lot of information on related variable like a mortality, jobs, marriage etc [10]. The study of the first episode psychosis was compared with a Canadian study with a similar sample has thrown up some interesting cross cultured finding. Both the study have been stopped however there was the need to promote awareness about the disorder [11]. In early detection and prevention of chronicity and disability was very limited due to scarcity human resources and low research budget issues [12]. Over 90 percent severely ill patients live with their families this is not only because families are billing to care for them, but also because alternative option for care are practically nonexistence however there is a need of medical attention to them in various community care centers. The number of hospital bed in the entire country is inadequate to provide patient care in which some non-governmental organization run community based center of care and rehabilitation. These are only a few besides many of these are in the southern state of Tamilnadu, Karnataka and Kerala [13]. There is need for community based care for such patients so that they may not be disgraced by the society. They should also get medical care and psychological based rehabilitation. There must be focus on mental health literacy in the general population in the recent concluded randomized control trial in India where the effectiveness of a collaborative community based care visited the home of the patient to deliver was compared with facility based care with Alzheimer and their families. It was seen that the intervention of the community health worker was acceptable and effectively especially who were more symptomatic and had greater disability. The feasibility of an effectiveness of delivery psychological intervention through was established [14]. Critical strategies for rehabilitant have been the use of low community volunteers trained in recognition identification and referral of person with mental disorder performing the first level of rehabilitation has also been facilitated by networking governmental and non-governmental organization. Involved in social and developmental activities. The non-governmental also embarked on community based programs. Which also officious and cost effective were also restricted by their development of time limited funding [15]. However collaboration with non-governmental organization is seen as an important approach to reach out to a wide geographic area. With a share economic commitment of the share collaboration. There have also been one of has been the use of mobile tale psychiatry by the Alzheimer's association Alzheimer association use the mobile psychiatry technique. A bus fitted with mobile equipment has been delivered mental health care to the population part of the pudukotta district and widely accepted by the local population [16].The community based programs have suffered from poor allocation of resources insensitivity to the needs of people with mental illness on apart of both professional and policy planners and indifference to mental health in general sustainability and continuity of programs most program are time bond projects. Contingent upon the funding resources [17].The priority is our country is to make the District mental health program more effective and efficient promote more community based service reducing the dependence on big hospital and reducing stigma living with Alzheimer's is no easy matter for person with disorder and their families need to be geared to enhancing facilities in the community for these person and improve awareness about this condition which in turn will facilities early treatment and social inclusions [18].

\section{TYPES OF ALZHEIMER DISEASE}

There are two types of AD i.e. early onset Alzheimer and late onset Alzheimer [19]. Early onset Alzheimer is a type of disorder that strike before the age of 65. There is no cure, but there are certain drugs to manage symptoms including memory loss, problems of sleeping and change in behavior. The early form of Alzheimer most often shows up at the age of 40s and 50s but symptoms can show up early. Late onset Alzheimer's is the most common form of the disease which happens to people age 65 and older. It may or may not run in families. So far researcher hasn't found a particular gene that related to late onset of Alzheimer [20]. 


\section{DIAGNOSIS}

There is no one way to diagnose AD. However there are various symptoms and diagnostic test used in combination. One of the most important aspects to diagnose $\mathrm{AD}$ is that there must be at least two of the four major symptoms present over a period of time. The main motor symptoms are loss of memory, slowness of movement called bradykinesia, loss of balance with possible falls. Other than these there are following scanning systems used in the diagnosis of $\mathrm{AD}[21,22]$.

\section{POSITRON EMISSION TOMOGRAPHY}

All the more as of late the primary capacities for PET are centered around the investigation of neurotransmitters (electrochemical signs went starting with one mind cell then onto the next to impart), the activities of pharmaceutical medications and the outflow of particular qualities in the cerebrum. Also, as of late a couple PET tracers have been created that join exclusively to the protein beta amyloid, which develops in the brains of patients with mild cognitive impairment (MCI) and Alzheimer's ailment. PET imaging with these specialists has the potential, alongside intellectual tests, to analyze Alzheimer's infection in patients, and to distinguish designs that may foresee which patients with MCI will build up Alzheimer's ailment. All the more as of late the principle capacities for PET are centered around the investigation of neurotransmitters (electrochemical signs went starting with one cerebrum cell then onto the next to convey), the activities of pharmaceutical medications, and the statement of particular qualities in the mind. psychological tests, to analyze Alzheimer's sickness in patients, and to recognize designs that may anticipate which patients with MCI will build up Alzheimer's infection [23, 24]

\section{ELECTRO ENCEPHALON GRAPH}

EEG measures the electrical movement of neurons as recorded from anodes set along the scalp. MEG (Magnetic encephalon graph) maps cerebrum action by measuring attractive fields that are produced by neural action in the mind. Both EEG and MEG give data about worldwide and additionally provincial neural action, however with MEG there is less twisting of the electrical signs. Regularly either of these electrophysiological techniques is joined with fMRI or PET to give integral data about ordinary and aggravated cerebrum EEG is utilized clinically to quantify physiological signs of strange cortical edginess, essentially in the determination and administration of epilepsy and other seizure issue. It is additionally utilized with other numerous different measures in serious consideration to screen head-harmed patients in trance like state, giving data that helps doctors evaluate patients' forecast. EEG is likewise used to study rest issue. EEG recordings can be led while a patient is inside the MR scanner. EEG and fMRI are utilized together, for occurrence, to restrict where in the cerebrum a seizure begins and where it spreads from that point $[25,26]$

\section{FUNCTIONAL MAGNETIC RESONANCE IMAGING}

Functional MRI (fMRI) demonstrates the mind in real life; researchers use it broadly to explain forms required in higher subjective working. It is very touchy so it can recognize little changes, and is moderately reasonable contrasted with PET, so it is the technique for decision for distinguishing territories of the mind that are actuated when a man embraces a particular psychological or engine undertaking. It is a circuitous measure, in any case, in light of the fact that the time it takes for element changes to happen in blood stream is any longer than that for neurons to shoot their electrochemical messages. Functional MRI can be utilized to think about the revamping of capacity taking after damage to a solitary cerebrum region $[27,28]$.

\section{SINGLE PHOTON EMISSION COMPUTED TOMOGRAPHY}

An imaging innovation that is like PET is Single Photon Emission Computed Tomography (SPECT). It is utilized for the majority of the same purposes as PET, yet is not so much costly but rather more advantageous for clinical use. SPECT started to be broadly utilized clinically in the 1980s on the grounds that, not at all like PET, it distinguishes specifically discharged gamma-beams from economically accessible stable radioisotopes. These isotopes are bigger and have a more extended half-life than those utilized as a part of PET, yet the imaging is less exact. In this way, patients who are found in facilities other than at scholastic exploration 
establishments are significantly more prone to get SPECT. An imaging innovation that is like PET is Single Photon Emission Computed Tomography (SPECT). It is utilized for the greater part of the same purposes as PET, however is not so much costly but rather more helpful for clinical use. SPECT started to be broadly utilized clinically in the 1980s in light of the fact that, not at all like PET, it recognizes straightforwardly transmitted gamma-beams from economically accessible stable radioisotopes. These isotopes are bigger and have a more drawn out half-life than those utilized as a part of PET; however the imaging is less exact. Along these lines, patients who are found in facilities other than at scholarly research foundations are much more prone to get SPECT. [29, 30]

\section{DAT SCAN}

DAT is used to examine Dementia with Lewy bodies (DLB) which is one of the main differential a parameter in diagnosis ofAD.DATscan is an imaging innovation that utilizes measures of a radioactive medication to detect loss of dopaminergic neurons in a man's cerebrum [31]

\section{DIFFUSE OPTICAL TOMOGRAPHY}

Diffuse optical tomography is 3D non-obtrusive procedure in which close infra-red light is utilized to record the inside piece of cerebrum oxygenation and other physiological change in brain. Diffuse optical tomography framework utilizes time dependent 3D volumetric images for detecting abnormalities in networks comprising the dorsal occipito-parietal cortex in $\mathrm{AD}$ [32].

\section{DIFFUSE TENSOR IMAGING (DTI)}

It is a molecular imaging innovation used to think about biochemical action that happens profound inside the tissues of live lab animal models. Close infrared (IR) light is utilized as a part of mix with fluorescent tests. Light of a particular wavelength is sparkled on the creature; thus this light energizes the objective particle to emanate light at an alternate wavelength, which is observed by tomographic locators set around the creature to gather light originating from different bearings. PCs join the various individual perspectives into threedimensional pictures [33].

\section{TREATMENT}

There is no standard for the disease the treatment for each person is based on his or her symptoms Treatment includes medication and other therapy. Other treatment include life style modification like getting more rest and more exercise Modification commonly prescribed alternative therapy and other treatment are available But commonly we use two following treatment i.e. Pharmacological treatment and Psychological treatment

There is no standard for the disease, the treatment for each person is based on his or her symptoms seductive and sleeping pills. Medicines are given by different routes such as dorsal routes and penetration routes $[34,35]$

Psychological therapy: It guides them through the process of understanding clients and their problems and developing solution Psychotherapy theories provide a framework for therapists and counselors to interpret a client's behavior, thoughts, and feelings and help them navigate a client's journey from diagnosis to posttreatment. Theoretical approaches are an understandably integral part of the therapeutic process. But with so many different methods out there, how do you know which counseling approach works best for you? Whether you're a student learning about counseling theories or a client looking for the right therapist, the following detailed descriptions will give you a deeper understanding of each counseling method. These theories are integrated throughout the curriculum are built into a foundation grounded in the psychodynamic perspective

\section{THERE ARE FIVE BROAD CATEGORIES OF PSYCHOLOGICAL THERAPY}

This therapy is changing on problematic behaviors. Behavior feeling and thought discovering by unconscious motivation psychoanalytical therapy are close working between therapist and patient. Psychoanalysis are closely identified with Sigmund Freudit has been modified since his early formation 
.Psychoanalysis or psychodynamic theory, also known as the "historical perspective," has its roots with Sigmund Freud, who believed there were unconscious forces that drive behavior. The techniques he developed, such as free association (freely talking to the therapist about whatever comes up without censoring), dream analysis (examining dreams for important information about the unconscious), and transference (redirecting feelings about certain people in one's life onto the therapist) are still used by psychoanalysts today [37,38].

\section{Behavior Therapy}

Behavioral therapy emphasizing the condition of person's undesirable behavior through pavlovian condition several variation have develop since behavior therapy. The variation is cognitive behavioral therapy (CBT) which focused on thoughts and behaviors. Behavioral theory is based on the belief that behavior is learned. Classic conditioning is one type of behavioral therapy that stems from early theorist Ivan Pavlov's research. Pavlov executed a famous study using dogs, which focused on the effects of a learned response (e.g., a dog salivating when hearing a bell) through a stimulus (e.g. pairing the sound of a bell with food). B. F. Skinner developed another behavioral therapy approach, called operant conditioning. He believed in the power of rewards to increase the likelihood of a behavior and punishments to decrease the occurrence of a behavior. Behavioral therapists work on changing unwanted and destructive behaviors through behavior modification techniques such as positive or negative reinforcement $[39,40]$

\section{COGNITIVE THERAPY}

In the 1960s, psychotherapist Aaron Beck developed cognitive theory. This counseling theory focuses on how people's thinking can change feelings and behaviors. Unlike psychodynamic theory, therapy based on cognitive theory is brief in nature and oriented toward problem solving. Cognitive therapists focus more on their client's present situation and distorted thinking than on their past. Cognitive and behavioral therapy are often combined as one form of theory practiced by counselors and therapists. Cognitive behavioral therapy, or CBT, has been found in research to help with a number of mental illnesses including anxiety, personality, eating, and substance abuse disorders [41].

\section{HUMANISTIC THERAPY}

Humanistic therapy is a way of dealing with situation or problems which tried to do justice with the whole person including mind, body and spirit. This method recognizes the self-healing capacities of the client. The humanistic therapy the works toward an authenticmeetingof equal in the therapy relationship. Abraham Maslow is perhaps the best known theorist peer with humanistic psychology.Humanistic therapists' care most about the present and helping their clients achieve their highest potential. Instead of energy spent on the past or on negative behaviors, humanists believe in the goodness of all people and emphasize a person's self-growth and self-actualization. Humanistic theories include client-centered, gestalt, and existential therapies. Carl Rogers developed client-centered therapy, which focuses on the belief that clients control their own destinies. He believed that all therapists need to do is show their genuine care and interest. Gestalt therapists' work focuses more on what's going on in the moment versus what is being said in therapy. Existential therapists help clients find meaning in their lives by focusing on free will, self-determination, and responsibility [42].

\section{HOLISTIC THERAPY}

Holistic therapy means drawing on and blending specific types of therapies. This approach is not linked to one particular type of therapy as those practicing integrative counseling do not believe that only one approach works for each client in all situations.Holistic and integrative therapy involves integrating various elements of different theories to the practice. In addition to traditional talk therapy, holistic therapy may include nontraditional therapies such as hypnotherapy or guided imagery. The key is to use the techniques and psychotherapy tools best suited for a particular client and problem. There are various therapies that counselors can choose to study, but the type of theory matters less than the success of the relationship between client and therapist. In the Counseling at Northwestern online Master of Arts in Counseling Program, students are prepared to become self-reflective practitioners and learn to examine the factors that influence the client-therapist relationship to become successful counselors [43]. 


\section{FUTURE PROSPECTS}

ADis a neurodegenerative condition that cause cognitive decline for around 60 percent of all reported cases which also includes other forms of dementia. Alzheimer is debilitating condition in which the victims find it increasingly difficult to perform the everyday task necessary for independent living and eventually require health and social care services. There are two major types of AD early onset Alzheimer's and late onset AD. Alzheimer's late onset that can affect after 65 years of age and is the more common disorder being responsible for around 90 percent of all cases. Early onset can affect before age 65 and is rare accounting less than 10 percent cases over all. AD is characterized by extracellular deposition of the amyloid beta peptide (Abeta), intracellular neurofibrillary tangles (NFT) appearance, cholinergic deficit, extensive neuronal loss as well as synaptic changes in the cerebral cortex, hippocampus and other areas of brain necessary for cognitive and memory functions[44].Ephirin signaling pathway is the target to treat some symptoms of AD. Molecule markers involved in the pathology of AD, includes Apo lipoprotein (ApoE), presenilin genesPSI,PS2 and APP, they are also found to impact adult neurogenesis in the hippocampus region of brain[44].

\section{CONCLUSION}

Alzheimer's is a disorder of mind affecting 1-3 percent of the population suffers globally. It has been the greatest disorder of old age. According to WHO Alzheimer's rank among the top three illness causing death.Currently no standard treatment of this disease. There is immediate need for the treatment of AD.

\section{ACKNOWLEDGEMENTS}

I am thankful to Sharda University for giving the opportunity to work as project research fellow of Ramalingaswamy project under supervision of Dr. Pankaj Taneja. I also express my gratitude towards my parents and friends for their inspiration to me for excelling in science.

\section{REFERENCES}

[1] Scheltens P, Blennow K, Breteler MM, de Strooper B, Frisoni GB, Salloway S, Van der Flier WM . Alzheimer's disease. Lancet. 2016 S0140-6736(15)01124-1

[2] Mendez MF,Early-onset Alzheimer's disease: nonamnestic subtypes and type 2 AD. Archives of Medical Research, 43, 2012, 677-85.

[3] Whiteford HA, Ferrari AJ, Degenhardt L, Feigin V and VosT, The Global Burden of Mental, Neurological and Substance Use Disorders: An Analysis from the Global Burden of Disease Study, PLoS One, 10,2010

[4] Murra CJ and Lopez AD, Global mortality, disability, and the contribution of risk factors: Global Burden of Disease Study. Lancet349, 1997, 1407-86.

[5] Goldman JS, Genetic testing and counseling in the diagnosis and management of young-onset dementias, PsychiatrClin North Am, 38, 2015,295-308.

[6] Bertram LandTanzi RE, The current status of Alzheimer's disease genetics: what do we tell the patients?Pharmacol Res, 50, 2004, 385-96.

[7] Gelman CR and Greer C, Young children in early-onset Alzheimer's disease families: research gaps and emerging service needs,Am J Alzheimers Dis Other Demen, 2011, 2629-35.

[8] Martin C, Solís L, Concha MI and Otth C, Herpes simplex virus type 1 as risk factor associated to Alzheimer disease, Rev Med Chil, 139, 2011, 779-86.

[9] Carolien NH, Abheiden, Rebecca van Doornik, Annet M. Aukes,Wiesje M. van der Flier, Philip Scheltens, and Christianne JM de Groota, Hypertensive Disorders of Pregnancy Appear Not to Be Associated with Alzheimer's Disease Later in Life, Dement GeriatrCogn Dis Extra,5, 2015, 375-385.

[10] Thara R, The Madras longitudinal study, Indian J Psychiatry 54, 2012, 134-7.

[11] Iyer SN, Mangala R, Thara R and Malla AK, Preliminary findings from a study of first-episode psychosis in Montreal, Canada and Chennai, India: comparison of outcomes. 121, 2010, 227-33.

[12] Patel V and Thara R, Meeting the mental health challenges: role of NGO initiatives. New Delhi: SAGE Publications; 2003. 
[13] Thara R, Islam A, Padmavati R. Beliefs about mental illness: 15. a study of a rural south-Indian community. Int J Ment Health 1998; 27: 70-85.

[14] Janardhan and Naidu (2007) Mental Health in India: an over view, CHC publication, circulated during national assembly on health of Janaarogya Andolona

[15] Chatterjee S, Pillai A, Jain S, Cohen A, Patel V. Outcomes of people with psychotic disorders in a community-based rehabilitation programme in rural India. Br J Psychiatry 2009; 195: 433-9.

[16] Thara R, Sujit J. Mobile telepsychiatry in India. World Psychiatry 2013; $12: 84$.

[17] JC Millan-Calenti, M Gandoy-Crego, M Antelo-Martelo, M Lopez-Martinez MP Riveiro-López, JM Mayan-Santos.

[18] Rossor MN, Iversen LL, Reynolds GP, Mountjoy CQ, Roth M. Neurochemical characteristics of early and late onset types of Alzheimer's disease. Br Med J (Clin Res Ed). 1984; 31;28:961-4.

[19] Rossor MN, Iversen LL, Reynolds GP, Mountjoy CQ, Roth M. Neurochemical characteristics of early and late onset types of Alzheimer's disease. Br Med J (Clin Res Ed). 1984 Mar 31;288(6422):961-4.

[20] Kumar A, Singh A, Ekavali. A review on Alzheimer's disease pathophysiology and its management: an update. Pharmacol Rep. 2015 67(2):195-203

[21] Campos C, Rocha NB, Vieira RT, Rocha SA, Telles-Correia D, Paes F, Yuan T, Nardi AE, Arias-Carrión O, Machado S, Caixeta L. Treatment of Cognitive Deficits in Alzheimer's disease: A psychopharmacological review. Psychiatr Danub. 2016 Mar;28(1):2-12.

[22] Agrawal M, Biswas A. Molecular diagnostics of neurodegenerative disorders. Front Mol Biosci. 2015 22;2:54

[23] Shimojo M, Higuchi M, Suhara T, Sahara N. Imaging Multimodalities for Dissecting Alzheimer's Disease: Advanced Technologies of Positron Emission Tomography and Fluorescence Imaging. Front Neurosci. 2015 Dec 22;9:482

[24] Oukoloff K, Cieslikiewicz-Bouet M, Chao S, Da Costa Branquinho E, Bouteiller C, Jean L, Renard PY. PET and SPECT Radiotracers for Alzheimer's Disease. Curr Med Chem. 2015;22 (28):3278-304.

[25] Tsolaki A, Kazis D, Kompatsiaris I, Kosmidou V, Tsolaki M. Electroencephalogram and Alzheimer's disease: clinical and research approaches. Int J Alzheimers Dis. 2014;2014:349249.

[26] Hulbert S, Adeli H. EEG/MEG- and imaging-based diagnosis of Alzheimer's disease. Rev Neurosci. 2013;24(6):563-76

[27] Bachert P, Schroder L, (2003), 'Magnetic resonance imaging spectroscopy'. Radiology. 43(12):1113-26

[28] Montagne A, Nation DA, Pa J, Sweeney MD, Toga AW, Zlokovic BV. Brain imaging of neurovascular dysfunction in Alzheimer's disease. Acta Neuropathol. 2016 ;131(5):687-707

[29] Oukoloff K, Cieslikiewicz-Bouet M, Chao S, Da Costa Branquinho E, Bouteiller C, Jean L, Renard PY. PET and SPECT Radiotracers for Alzheimer's Disease. Curr Med Chem. 2015;22 (28):3278-304.

[30] Brigo F, Turri G, Tinazzi M 123I-FP-CIT SPECT in the differential diagnosis between dementia with Lewy bodies and other dementias. J Neurol Sci. 2015 Dec 15;359(1-2):161-71

[31] Vaamonde-Gamo J, Flores-Barragán JM, Ibáñez R, Gudín M, Hernández A. DaT-SCAN SPECT in the differential diagnosis of dementia with Lewy bodies and Alzheimer's disease Rev Neurol. 2005 Sep 115;41(5):276-9.

[32] Landy KM, Salmon DP, Filoteo JV, Heindel WC, Galasko D, Hamilton JM. Visual search in Dementia with Lewy Bodies and Alzheimer's disease: Cortex. 2015 Dec;73:228-39

[33] Le Bihan D, Mangin JF, Poupon C, Clark CA, Pappata S, Molko N, Chabriat H. 'Diffusion Tensor Imaging: Concepts and Applications. Journal of MagneticResonance Imaging, 13:534-546

[34] Cooper, J.R., Bloom, F.E., Roth, R.H. The biochemical basis of neuropharmacology. in: Oxford University Press, New York; 1996.

[35] Galimberti D, Scarpini E. Treatment of Alzheimer's disease: symptomatic and disease-modifying approaches. Curr Aging Sci. 2010 Feb;3(1):46-56.

[36] Burns, Alistair, Else Guthrie, Federica Marino-Francis, Charlotte Busby, Julie Morris, Eve Russell, Frank Margison, Sean Lennon, and Jane Byrne. "Brief psychotherapy in Alzheimer's disease." The British Journal of Psychiatry 187, no. 2 (2005): 143-147.

[37] Galimberti D, Scarpini E.Treatment of Alzheimer's disease: symptomatic and disease-modifying approaches Curr Aging Sci. 2010;3(1):46-56. 
[38] Puentes WJ.Using an associational trends framework to understand the meaning of obsessive reminiscence.J Gerontol Nurs. 2008 Jul;34(7):44-9.

[39] Lima-Silva TB, Bahia VS, Carvalho VA, Guimarães HC, Caramelli P, Balthazar ML, Damasceno B, Bottino CM, Brucki SM, Nitrini R, Yassuda MS. Direct and indirect assessments of activities of daily living in behavioral variant frontotemporal dementia and Alzheimer disease. J Geriatr Psychiatry Neurol. 2015 28(1):19-26.

[40] Lima-Silva TB, Bahia VS, Carvalho VA, Guimarães HC, Caramelli P, Balthazar ML, Damasceno B, Bottino CM, Brucki SM, Nitrini R, Yassuda MS. Neuropsychiatric Symptoms, Caregiver Burden and Distress in Behavioral-Variant Frontotemporal Dementia and Alzheimer's Disease. Dement Geriatr Cogn Disord. 2015;40(5-6):268-75.

[41] Reisberg B, Ferris SH, de Leon MJ, et al. The stage specific temporal course of Alzheimer's disease: functional and behavioral concomitants based upon cross-sectional and longitudinal observation. In: Iqbal K, Wisniewski HM, Winblad B, Alzheimer's disease and related disorders. New York: Alan R. Liss Inc., 1991:23-41.

[42] Alison marriott, catherine donaldson, nicholas tarrier, alistair burns. The British journal of psychiatry 2000, 176 (6) 557-562

[43] McCabe L A holistic approach to caring for people with Alzheimer's disease.Nurs Stand. 2008 $1 ; 22(42): 50-6$.

[44] M.S Parihar, Taruna Hemnani Alzheimer's disease pathogenesis and therapeutic interventions Journal of Clinical Neuroscience Volume 11, Issue 5, 2004, Pages 456-467. 